Research in Drama Education: The Journal of Applied Theatre and Performance

\title{
Environmental aesthetics, social engagement and aesthetic experiences in Central Asia
}

\section{Ananda Breed}

To cite this article: Ananda Breed (2015) Environmental aesthetics, social engagement and aesthetic experiences in Central Asia, Research in Drama Education: The Journal of Applied Theatre and Performance, 20:1, 87-99, DOI: 10.1080/13569783.2014.986447

To link to this article: https://doi.org/10.1080/13569783.2014.986447

册 Published online: 27 Feb 2015.

Submit your article to this journal $\pi$

Цlll Article views: 187

Q View related articles $\square$

View Crossmark data ¿

Citing articles: 1 View citing articles ¿ 


\title{
Environmental aesthetics, social engagement and aesthetic experiences in Central Asia
}

\author{
Ananda Breed ${ }^{\mathrm{a}, \mathrm{b} *}$ \\ a Interweaving Performance Cultures International Research Centre, Freie Universität, \\ Berlin, Germany; ${ }^{b}$ Applied Theatre and Performance, BA (Hons) Drama, University of East \\ London, UK
}

\begin{abstract}
In this essay, I explore the Youth Theatre for Peace (YTP) project in relation to environmental aesthetics and engaged participatory practices towards tolerance building in Central Asia. My main argument is that cultural histories of storytelling, manas (an oral and now literary Kyrgyz epic) and trickster tales incorporate ideas and narratives that are useful in negotiating the ambiguities between differing moral, political and social agendas and can be drawn on in conflict negotiation contexts. I argue that environmental aesthetics offers a useful theoretical framework for analysing the YTP project due to the nomadic eco-spirituality and ecoconsciousness of the region. Further, specific (embodied and emplaced) performing arts activities provide opportunities for communities to build longer-term strategies for engaging with and intervening in the political realities in which they live.
\end{abstract}

\begin{abstract}
Khan ruled the land through force. One day, he heard about the indescribable beauty of a poor nomad's daughter, Ayana, and decided that he must have her for himself. Ayana lived in a village and was in love with the beauty of the mountains and the river. Often, she would sit next to the water and sing. She had many suitors, but she rejected them happiest to spend time in nature and with her father. Khan sent matchmakers to her with gifts, but she refused them. Eventually, Khan sent his riders to capture her. Ayana was blind folded and taken to the fortress. Khan continued to shower her with gifts, but she refused them all. Like a wild beast, Khan attacked her. Ayana leapt to the window. As she fell, the fortress crumbled, the rivers flooded the valley, and the girl sank to the bottom of what is now Issyk-Kul Lake. You can hear her singing, even today. ${ }^{1}$
\end{abstract}

Youth and adults of the Youth Theatre for Peace (YTP) project created response performances to the folk tale of Issyk-Kul lake based on the issue of bride kidnapping; a particularly violent re-imagined practice reported to constitute half of all marriages in Kyrgyzstan (Kleinbach and Salimjanavoa 2007). ${ }^{2}$ The folk tale was also used to explore how nature and the environment would be incorporated into performance making and to develop characterisation using archetypal figures from Kyrgyz culture. The use of the environment within the folk tale and the theatrical response is interrelated to the eco-spiritual and eco-consciousness of nomadic tribes in Central

*Email: a.breed@uel.ac.uk 
Asia characterised by Zoroastrianism, Tengrianism, Buddhism, Christianity and Islam that lends itself towards the use of culture for tolerance building. ${ }^{3}$

In this essay, I will explore the YTP project in relation to environmental aesthetics and engaged participatory practices towards tolerance building in Central Asia. My main argument is that cultural histories of storytelling, manas (an oral and now literary Kyrgyz epic) and trickster tales incorporate ideas and narratives that are useful in negotiating the ambiguities between differing moral, political and social agendas and can be drawn on in conflict negotiation contexts. I argue that environmental aesthetics offers a useful theoretical framework for analysing the YTP project due to the nomadic eco-spirituality and eco-consciousness of the region. Further, specific (embodied and emplaced) performing arts activities provide opportunities for communities to build longer-term strategies for engaging with and intervening in the political realities in which they live.

To analyse the correlation between aesthetics, environment and socially engaged practices, I will frame the YTP project through environmental aesthetics scholar Yrjö Sepänmaa's theorisation of aesthetics to describe, to interpret and to evaluate the environment (Sepänmaa 1986, 79). Sepänmaa defines environmental aesthetics with an initial definition of environment:

\begin{abstract}
The environment is that which surrounds us (in the centre of which we are as observers) which we perceive with our various senses, in the sphere of which we move and have our being ... Environments are extremely varied; they may be nature in a natural state or a cultural environment. In the broadest possible concept environments are also our culture with its sub-areas, even our intellectual atmosphere: science, art, and religion, as well as work and play, human relations and social systems. (Sepänmaa 1986, 15-16)
\end{abstract}

This essay will address varied human relations and social systems as an aesthetic experience. According to peacebuilding scholars Cynthia Cohen, Roberto Varea and Polly Walker:

\begin{abstract}
We use the term aesthetic to refer to the resonant interplay between expressive forms of all cultures and those who witness and/or participate in them. There are several defining features of 'aesthetic experience' - or aesthetic interaction with artfully composed expressive forms, such as songs, images, gestures and objects. First, aesthetic experiences involve people in forms that are bounded in space and time (e.g. by the frame around a picture, or the lights fading to black at the end of a play). Secondly, aesthetic experiences engage people on multiple levels at the same time - sensory, cognitive, emotive and often spiritual - so that all of these dimensions are involved simultaneously in constructing meaning and framing questions. Thirdly, aesthetic experiences engage people with forms that are able to acknowledge and mediate certain tensions, including those between innovation and tradition, the individual and the collective. Because of these defining features, an aesthetic experience is one in which an enlivening sense of reciprocity arises between the perceivers/participants and the forms with which they are engaging. (Cohen, Varea, and Walker 2011,6)
\end{abstract}

Environmental aesthetics and aesthetic experiences are used as a framework to understand the YTP project, with the project even extending that framework in new directions from which the act of performance making serves to re-negotiate relationships, patterns of communication and structures of power. I will provide a critical examination of the project with an emphasis on how the social relations and 
local decision-making processes are part of the environmental aesthetic and aesthetic experiences more generally.

\section{Youth Theatre for Peace}

Kyrgyzstan is surrounded by the mountainous borders of China to the east, Uzbekistan to the west, Kazakhstan to the north and Tajikistan to the south. Ethnic and social tension exists between Kyrgyz and Uzbeks and between Kyrgyz and Tajiks in southern Kyrgyzstan. One of the reasons for this is primarily due to the carving out of borders, so that there were no distinct boundaries between countries, ${ }^{4}$ which have led to ongoing conflict on issues such as land rights and water. There is a tendency for these conflicts to escalate, especially in the southern part of the Fergana Valley. However, this tension does not usually take such a violent form as, for example, during the clashes between ethnic Kyrgyz and Uzbeks in 2010. In the city of Osh located in southern Kyrgyzstan, 470 people, mostly Uzbeks, were killed, 300,000 were forced to leave their homes and 110,000 fled over the border in June 2010. The outbreak of ethnic violence, primarily between Kyrgyz and Uzbeks, spread across Kyrgyzstan into northern Kyrgyzstan and the capital Bishkek. The noted violence in June 2010 following the overthrow of former president Kurmanbek Bakiyev reflected growing strains among identity groups in the country, weakening rule of law and corruption under the Bakiyev regime. The YTP project was implemented by the International Research \& Exchanges Board (IREX) in early 2010, prior to the June 2010 events, to address the mounting tensions between ethnic groups; thus, the project switched from being primarily preventative to working within violent contexts.

YTP originated through a pilot project in Indonesia entitled Promoting Tolerance and Dialogue through Interactive Theatre (2008-2010) funded by the British Embassy and IREX Europe, an international non-profit development organisation; this project developed into a second, 2010-2014 USAID-funded project in Kyrgyzstan and Tajikistan entitled Youth Theatre for Peace. The third project, UNICEF's Interaction of Young People: across ethnic lines and public discourse on youth's role in building peace and strengthening tolerance (2012-2014) was similar in design to the previously noted projects but with the specific objective to improve the interaction of youth in the Osh and Jalalabad regions of Kyrgyzstan. I served as the lead facilitator, curriculum designer and consultant of these projects. Responsibilities for the projects in Kyrgyzstan included writing training manuals and curricula; training 60 trainers from the Chui and Batken oblasts (provinces), Naryn and Talas oblasts and Osh and Jalalabad oblasts in participatory practices and workshop design; and overseeing the facilitation and development of training materials for four 7-day training of trainers (TOT), seven 12-week intensive youth camps and three 7-day sustainability workshops involving more than 500 adults and young people (inclusive of workshops for IREX and a subsequent project that I conducted with UNICEF). All three projects worked in collaboration with local partners including the Centre for Civic Education Indonesia (CCEI) and Kyrgyzstan's Foundation for Tolerance International (FTI).

The overall structure of each project began with an initial scoping visit, in which I consulted with artists, educators, government officials, cultural ministers, religious and community leaders, NGOs (that used theatre to respond to conflict issues), conflict specialists and community-based organisations. These consultation meetings were used to receive guidance concerning what kinds of methodologies might be 
used or avoided, to determine who might be involved in the project and the selection process and to gain knowledge about conflict issues. Following the initial consultation meetings with varied stakeholders, schools and community-based organisations were approached to recruit interested individuals into the project as adult trainers and youth participants. A part of the selection criteria was based on one's knowledge and experience of local conflict issues, familiarity with cultural forms and ability to implement methodology into schools, and community-based organisations, through drama clubs and theatre tours. Often, selected individuals were singers, dancers and musicians alongside serving as community organisers. Recruitment contained a three-tier process of first introducing the programme through a community meeting followed by a participatory workshop that demonstrated some of the varied techniques that might be employed for dialogic purposes. Members of FTI and IREX interviewed interested individuals, and selection was further determined by the necessity for equal representation of age, gender, ethnicity and language.

Partners included a professional theatre troupe, Sakhna, from Bishkek (Kyrgyzstan) that provided 12 artists - a mixture of actors, dancers and musicians - who worked alongside the YTP project to support the artistic development of the participants and to provide workshops.

Sakhna's work served as an artistic model to develop reception to the environment through their use of manas, traditional instruments and evocation of nature. Sakhna was founded under the direction of Nurlan Asanbekov in 2002 and performs traditional manas through a mixture of nomadic cultural forms and contemporary performance practices influenced by pre-Soviet, Soviet and postSoviet conventions. ${ }^{5}$ Core to their pedagogy and practice was the elemental use of nature to inform characterisation, staging and presence. Asanbekov noted that the work emerged from 40 eposes (Epoz) - or smaller renditions of the epic Manas stating that the reconstruction of identity in Kyrgyzstan required creating a new theatrical system; thus, there originated the idea of establishing the format for what he calls nomadic theatre. He comments on the powerful energy of the melodies and rhythm of verses including the amplitude and range of vocal vibrations. ${ }^{6}$ The embodiment of histories, memories and landscapes within the art form itself whether due to the relation of animism to the Kyrgyz art form, an historic nomadic past, or the transformational characteristics of participatory performance - inherently develops a unique environmental aesthetic. As part of their workshops, Sakhna focused on how to perceive the natural environment within the performance space.

For the first TOT conducted in Kyrgyzstan, adult trainers and artists from Sakhna worked together with myself and co-facilitator James Forrester, IREX staff, and FTI to exchange games and exercises, and to develop a skill -based curriculum that covered the following areas: acting skills, conflict analysis, cultural exchange, facilitation, trust building and project sustainability. Techniques were then tailored to a manual and a facilitation team of adult trainers including artists from Sakhna, and youth-serving professionals who delivered the curriculum in drama camps for youth between the ages of 15 and 16 . There was usually a three-month period of time between the initial scoping visit, the TOT and the implementation of the camps for materials to be adapted to local contexts. Trainers were encouraged to make adaptations specific to the communities in which they served. Following the youth camps, in which youth became co-facilitators and often lead facilitators, the participants developed drama 
clubs in their schools to extend the methodology to their peers. Drama clubs were then set up in each community and extended to theatre tours.

The drama clubs unilaterally contained membership of Kyrgyz, Tajik and Uzbek participants - one of the only spaces in Kyrgyzstan where language and culture other than Kyrgyz is encouraged and popularised. Due to the focus on building dialogue between adversarial groups, the YTP participants negotiate the varied use of cultural forms and language within the rehearsal and performance process. Trainers and youth participants received funding to develop drama clubs in their local communities and to create public performances with the objective to create dialogue about conflict issues. FTI served as an adviser to help approach these issues with a deep knowledge of systems on a local and governmental level. FTI continues to be one of the most experienced NGOs working on conflict prevention and resolution in Central Asia, working through grassroots structures and indigenous cultural mechanisms with an emphasis on conflict analysis, mediation and negotiation to build platforms for dialogue.

\title{
Cultural histories in conflict negotiation contexts
}

The YTP project included several exercises in which cultural forms were performed, taught and adapted between regions and across ethnic identities. The exercise Regional Exchange provided an opportunity for participants to devise a workshop based on a story, song, dance or game from their region. Often, this would include participants facilitating the regional context of a game or exercise, alongside embodied representations of their region. By embodied, I use Edward S. Casey's terminology concerning how the body integrates itself with the environment though a kind of corporeality based on perception. Thus, the body becomes a locality, a place and a space of knowledge. Casey states:

\begin{abstract}
Given that we are never without perception, the existence of this dialectic means that we are never without emplaced experiences. It signifies as well that we are not only in places but of them. Human beings - along with entities on earth - are ineluctably placebound. More event than earthlings, we are placelings, and our very perceptual apparatus, our sensing body, reflects the kinds of places we inhabit. The ongoing reliability and general veracity of perception (a reliability and veracity that countenance considerable experiential vicissitudes entail a continual attunement to place (also experienced in open-ended variation). But if this is true, it suggests that place, rather than being a mere product or portion of space, is as primary as the perception that gives access to it. (Casey 1996, 19)
\end{abstract}

In this way, perception and the body as place provides the knowledge to communicate and negotiate histories, geographies and topographies. YTP exercises contained regional specificity that included an evocation of place and space. Apricot orchards, mountains, lakes, rivers and the spirits in association with these places were personified through manas, poems, dances and songs. For example, the folk song Ashagulon was used as part of the regional exchange. Ashagulon is a folk song that is sung during a ritual ceremony that is conducted in the springtime by residents of the mountainous regions of Tajikistan. It is the residents' address to the heavens so that rain will fall. Much of the mountainous landscape is not irrigated, so many sown plots wither and die in the springtime when there is little precipitation. Because of this, 
residents look to the sky and ask for rain. They place a scarecrow among the plots. The elders and the young begin to play the doira drum and sing, circling around the scarecrow. The song begins with the following verses:

Ashaguloni rostina-e

Boron bibor bo ostina-e

One of the participants sang the main verse, while the others sang the chorus. While singing, everyone circled the scarecrow, playing the doira drum, as well as spoons and dishes. During the ritual, one of the participants pours water on the scarecrow. Although the ritual may have been particular to Tajikistan, the sharing of the ritual with the other participants encouraged the interchange between cultural practices, and to find connections on relational, phenomenological and topographical levels.

During another exercise, Community Box, participants created an installation of maps, photos, food, paintings, poems, dance and music to introduce participants from other regions to their daily lives. Exercises contained traditions, cultures, beliefs and stories to share the geographic and political landscapes of their environs. Senses were evoked through the smell, touch and taste of food particular to each region. Poetry, music and the visual arts provided context in terms of the location of place from where the participants were from to create a 'being-in-place' for participants.

Symbols and designs were used when reflecting upon experiences through visual art exercises. The semantics of ornamentation is common through traditions like felt carpet weaving. The carpets or shyrdak take approximately two months to weave and are usually constructed communally by one member of each family. In this way, the practice fosters the communal transmission of knowledge. The shyrdak are so named from the stitching that contains coded messages through symbols such as animals, deer horns and inscriptions. Symbols were used as elemental designs, among new signifiers and symbols that the young people created. Thus, the familiarity of using symbols as signifiers of meaning for varied experiences within the project like graffiti wall in which young people draw representations of their experiences as a reflective and evaluative exercise could be read as an integration of old and new from the origins of exercises to how they were adapted or woven anew to address contemporary issues through cultural practices.

In addition, both trickster tales and manas provide examples of how culture has historically been used at points of major social upheavals (Bellér-Hann and Sharshenova 2011, 72).

I will expand on these cultural forms to best historicise and contextualise how they might be used within conflict negotiation contexts.

\section{Trickster tales}

The Kuyruchuk trickster, based on a famous akin or minstrel from the 1900s, is the Kyrgyz rendition of Robin Hood. He served as a social critic and Kuyruchuk tales are often set at historical turning points accompanied by social transformations. The tales provide regional and cultural specificities that reflect ideological strategies.

Kuyruchuk was a character who developed from the journeys and encounters of a renowned akin named Kudaybergen Ömürzak who was born in Kizill-Tuu village in the Jumgal region, Naryn oblast in 1866. The tales follow his exploits until his death 
in 1940 (Bellér-Hann and Sharshenova 2011, 73). He was nicknamed 'Little Tail' for his ability to slip between social roles as a modern trickster character. Ildikó Bellér-Hann and Raushan Sharshenova note:

The Trickster has often been described as an incorrigible boundary crosser, who is both human and divine. ... Through breaking social roles and norms, the Trickster draws attention to them ... Thus the Trickster's disruptive and sometimes even destructive behaviour makes place for the new: he is a potentially creative force, a transformer. (Bellér-Hann and Sharshenova 2011, 76-77)

The following tale of Kuyruchuk demonstrates the ability of an akin to question systems of injustice and the rule of customary law:

Once Kuyruchuk came to Naryn on business. The street was full of people. It turned out that a well-known man, the robust Samankulak who did not even own a dog and whose roof was leaking, had been accused of robbery. Kazï accused him of stealing his nine horses and covering his tracks. Kazï hired a judge who sentenced Samankulak to twelve months' imprisonment and obliged him to pay his alleged debt of nine horses. Who would listen to poor Samankulak when the authorities and the judge were all in Kazi's hands? Having learned the details of the affair, Kuyruchuk stood up in front of the crowd and stated:

'Oh, silent crowd! Wise men! Listen, this is what I have to say!'

Those who did not know Kuyruchuk thought that the man was asking for trouble.

'Samankulak is not guilty', he stated. 'The man who accuses him has no idea who is guilty.'

Having seen Kuyruchuk, Kazï frowned and commanded:

'Well, if you are really such a brave man, show me the thief!'

Kuyruchuk answered.

'The thief is my nose.'

Kazï asked.

'What did he say?'

Kuyruchuk answered.

I've stolen your horses. Be fair to Samankulak and sentence me. I can give you your horses back within ten days.'

The judge thought for awhile, and questioned Samankulak again and again. Samankulak swore his innocence. The judge eventually decided that Samankulak was innocent, and started to question Kuyruchuk. Kuyruchuk turned to Kazi:

'Let's leave the stolen horses aside for a short time. Answer me, do you plead guilty for forcibly taking my horse and slaughtering it? Do you plead guilty to robbing the travelers who passed through your village? Try to prove your innocence in this matter in front of the people and the judge!'

Kazï, who up until then had been demanding the punishment of the guilty person, hung his head and admitted his guilt:

'It is true', he said.

The judge was perplexed; he did not know anymore who was the plaintiff and who was the accused saying:

'To hell with you all! You should settle your own accounts. Do it yourselves!' Having said this, he left, swinging his arms. The people were impressed with Kuyruchuk's presence of mind and courage. (Bellér-Hann and Sharshenova 2011, 110) ${ }^{7}$ 
This folk tale contains the scenario of Kuyruchuk as Robin Hood, presenting himself to be judged in place of the poor man who was accused of thievery and overturning juridical processes. Kuyruchuk engages with the legal structure to then reverse the outcome of the sentence, which leads the judge to vacate his position and to let the people settle their own accounts. In this way, Kuyruchuk positions himself between authorities and social structures foreign to Kyrgyzstan with the assertion of clever manipulations of the system for social justice, not necessarily supporting the overarching Soviet project. Thus, illustrating the historic role of culture and performance to address conflict issues.

Likewise, the characters and plots developed within the YTP project provided an opportunity to position oneself between authorities and social structures towards conflict negotiation practices.

\section{Manas}

The trilogy is based on the journey of Manas who served as a warrior and united ethnic clans within Central Asia. In this way, the word Manas is both the name of an historic warrior and subsequent manas epic that evolved into an oral history. Volume one is based on the birth of Manas to an elderly couple who were barren of children. He was born a full-grown boy equivalent to the age of six. Dreams provided early prophecy that Manas would lead Central Asia with the aid of 40 horsemen. When sent by his father to live with a shepherd to calm his naughty behaviour, he strays into the mountains where he meets 40 spirits, warriors who claim that they will eventually come to befriend him and that together they will both conquer and unite Central Asia. The volume describes the varied encounters and battles of Manas and his 40 knights and the negotiation between ethnic clans. Volume two focuses on Manas' son Semetei and Manas' wives, characters whom are often portrayed through theatre as strong women who often overpower Manas. This is a notable example of how the epics can be used within contemporary times for girls and women to be promoted within society through the framing of cultural forms and performed through theatre. One noted example of the representation of women through the manas include the following story. At a feast to mark a recent victory:

\footnotetext{
the maiden Saikal challenges everyone to a wrestling match on horseback. Saikal has a reputation and no-one dares to take the challenge. Finally, Manas steps up, shamed that he has to fight a woman to save the pride of his army ... A fierce battle follows, but Manas cannot beat her. Everyone around urges them to give up, and Manas is offered a prize to accept his victory and not kill her. The only prize that Manas would accept, however, is the maiden Saikal as a bride. But, Saikal disappears and does not show herself to Manas anymore. (van der Heide 1970, 89)
}

This passage is especially poignant for contemporary readings of manas, which are referred to as the record of history and the main code of ethical conduct, to negate the re-imagined practice of bride kidnapping as a 'traditional' practice. The volume three, Seitek, is based on Manas' grandson.

Magic and supernatural powers are evidenced throughout the manas trilogy and continue to be an aspect of the transmission from manas to the tellers or manaschi who often note that they were originally selected by spirits as children through dreams, and the stories and verses are passed through them without any 
formal training. Manaschi serve as 'intermediaries between humans and the supernatural' (van der Heide 1970, 99). There are different ways that manas can be interpreted. Although there are many examples of conflict in the epic, the focus on Manas unification of the 40 tribes is often cited as being an initiation of friendship and unity between tribes and nations.

Nurlan Asanbekov founded Sakhna to perform traditional oral manas through a mixture of nomadic cultural forms and contemporary performance practices influenced by pre-Soviet, Soviet and post-Soviet conventions. Asanbekov notes the significance of culture for connecting cultures and people towards peaceful coexistence:

The basis of Sakhna is to perform the epics. It is a mystic theatre and it explores the art of telling. It includes modern with traditional elements. To create tolerance, we need to raise the spirit and cultural level of people in Kyrgyzstan. Also, for artists to experiment with the cultural works of different countries. In this way, we create tolerance and understanding between countries. ${ }^{8}$

Core to their pedagogy and practice was the elemental use of nature to inform characterisation, staging and presence. Asanbekov noted the work emerged from 40 eposes - or smaller renditions of the epic manas - stating that the reconstruction of identity in Kyrgyzstan required creating a new theatrical system; thus, there originated the idea of establishing the format for what he calls nomadic theatre that influenced the training and implementation of the YTP project.

\section{Contemporary cultural strategies for engagement in political and social realities}

The noted examples from the trickster tales and manas evidence how culture was used to negotiate varied political and social realities. These same traces of resistance and potential transformation can be linked to the use of cultural strategies within the YTP project. Similar to the cultural histories of storytelling through manas and trickster tales, the YTP project draws on ideas and narratives that are useful in negotiating the ambiguities between differing moral, political and social agendas and can be drawn on in conflict negotiation contexts. YTP trainers integrated locally based systems of community and cultural governance into three primary stages including conflict mapping, community performances and drama clubs and theatre tours that integrated stakeholders into the process such as advisory councils, elders associations, resource management agencies and women's associations. Due to the focus on the project to create dialogue in order to resolve problems, a part of the aesthetic is focused on coordinating performances, so that parties important to the decision-making process are present. In order to portray a 'true to life' scenario, scripts are developed from the communities and staged to exemplify traditions and lifestyles. The aesthetic calls for a fundamental mimesis through simulation and enactment of political and social realities for an emotional, psychological, physical and spiritual response from the audience and the community at large.

In the case of Dilfuza, an Uzbek trainer whose family was targeted in the 2010 attacks, she noted the segregation between different ethnic groups and focused on the necessity to develop communication between these groups. Core to her project was the varied use of public space for the interaction of people. Her community was 
divided into four quarters - each quarter being made up of a different ethnic group and thus she selected to situate the performances in the centre, on the corner of each quarter. The performance demonstrated the ability to work between ethnic groups and languages. Since conflict over land and water resources is often core to regional and ethnic conflicts, while at the same time natural properties contain cultural and spiritual affiliations, the actual environments in which performances take place becomes a part of the aesthetic.

Syrga, an Uzbek trainer from Osh, conducted performances related to issues concerning the welfare of orphaned children. In Kyrgyzstan, there are government monies allocated to support orphans, but often these monies are either laundered elsewhere or do not go directly to orphans. In the case of Syrga, she worked with her drama club to highlight varied social consequences of conflicts regarding resources. One of the students in her school was orphaned and did not receive monies, thus experienced social exclusion and violence. His personal story was related to a conflict over water in his village. During a heated quarrel over water distribution, his father was hit over the head with a shovel and inadvertently killed. The boy was left with his three other siblings as orphans. Without monies, they were forced into early child labour, did not have appropriate clothing and were frequently ridiculed and mistreated. This story was staged in April 2013 for the school and surrounding community, with the inclusion of local authorities and social workers. Due to the impact of the production, local authorities developed an initiative to count the orphaned children in the community and to develop a transparent process to fund the orphans through government schemes. On 1 June 2013, International Children's Day, funds were publicly distributed to orphans. Local authorities started to track the progress and development of orphans. Resulting from the success of the project to address both the plight of orphans and violence in the schools, a conference was conducted with over 200 social workers from the region using the production as a primary tool for discussion and subsequent actions.

On a more systemic level, Halima, a Dungan trainer from Chui, works with the prosecutor's office to develop issue-oriented performances based on conflict issues and criminal activities. When she first started her drama club in 2010, local media wrote an article about how issues concerning suicide at a Turkish school had been addressed through drama. The prosecutor's office requested the drama club to create a performance about school racketeering and the prosecutors attended alongside atrisk youth. Following the performance and during the discussion, youth stated that police could not help them, and there was no response from police in the audience. What was evidenced during the discussion was the lack of initiative from the police to respond directly to the youth. The drama club was invited to work with the prosecutor's office to develop a participatory methodology of engaging youth and training the police to communicate more effectively. To date, there have been six different performances staged as collaborations between youth and the prosecutor's office. Audiences actively engaged with the dialogic performances, voicing suggested solutions to the staged conflict scenarios; those myriad proposed solutions informed policy-makers' discussion and debate both informally, through theatre performances, and formally, through meetings conducted with government officials before and after performances. 


\section{Conclusion}

To date, the YTP project has reached over 53,000 community members. ${ }^{9}$ There are now 10 master trainers in Kyrgyzstan who developed an independent NGO, launched a website with social networks linked to all YTP trainers and participants, and who currently conduct trainings for IREX, UNICEF and other NGOs and IOs as well as local constituents. One adult Tajik trainer and another Kyrgyz trainer have been publicly elected to local government positions, due to their use of participatory approaches to address conflict issues. There are several youth whom have continued their theatre practice to attend the University of Arts in Osh and one youth trainer who became the first girl president of her school. Drama clubs have won awards for their performances and often serve as intermediaries concerning local conflict issues. FTI noted that they have changed their practice to include the methodologies co-created through YTP as part of their institutional practice of working with communities. The Ministry of Education has created paid positions for $70 \%$ of all drama clubs, and the work of trainers has been recognised through the presentation of their work at international conferences based on the pedagogy of education in Russia, the Ministry of Education in Kyrgyzstan and the integration of YTP into open public debates with the prosecutor's office, the social institution working with orphans and water and land agencies. Participatory and socially engaged performance is new to the region, and individuals claim that its techniques provided the additional benefit of extending the ethos and practice of participatory approaches to the classroom environment.

The YTP project engaged with social processes to become a productive force in the aesthetic expression necessary for building tolerance - through the analysis and integration of systems that included local and national governmental structures and individuals linked to local and cultural systems of self-governance - reflective of the structures of environmental aesthetics as set out in this essay to serve as a dynamic force of establishing alternative structures and spaces for ethnic identity groups and multidimensional needs to be addressed. The original project based in the Chui and Batken oblasts escalated to extend to the Naryn and Talas oblasts and finally to Osh and Jalalabad oblasts. By the end of the project, the methodology had extended to every oblast in Kyrgyzstan, in which trainers and youth established drama clubs and theatre tours.

However, the objectives of the YTP project are inherently intertwined with international development rhetoric and political agendas. The framework of the project itself - based on the understanding and negotiation of political and social systems, the application of cultural artistic forms and the integration of decisionmakers into the overarching project from a local to a government level for tolerance building - focuses on the use of the performing arts as a vehicle for democratic structures of governance. Regardless of statistics from external evaluation of the YTP project that $98 \%$ of participants said they are confident in their ability to positively affect conflict situations in their community, compared to $31 \%$ of comparison group in Kyrgyzstan, there are larger national and international forces that affect local conflict issues. $^{10}$

This essay describes a particular social and political process in Kyrgyzstan that emerged from particular contexts related to conflict and violence between 2010 and 2014. Although I initially trace the historic trajectory of how cultural forms including manas and trickster tales have been used to negotiate the ambiguities between 
differing moral, political and social agendas, the same processes that can be used towards unification can be used for exclusion. For example, the manas epic that contain historic and legendary accounts of the unification between ethnic groups has also been increasingly re-imagined as a Kyrgyz cultural form to fuel nationalism in Kyrgyzstan, diminishing the role that the manas once played to promote cohesion between ethnic groups. In this way, cultural forms can be co-opted and potentially re-framed for practices that can lead to conflict. Additionally, although the manas were once used to instil moral and social values, varied codes and signifiers are no longer unilaterally relevant and the art of reciting manas has waned. In this way, although I have framed the YTP project in relation to environmental aesthetics and aesthetic experiences that are informed by the adaptation of cultural forms in Central Asia, these same forms and systems can be manipulated for alternative purposes.

\section{Acknowledgement}

Special thanks to Erika Fischer-Lichte, Christel Weiler, Gabriele Brandstetter, Matthias Warstat, Holger Hartung, Torsten Jost and Claudia Daseking from the Interweaving Performance Cultures International Research Centre. Also, to IREX and UNICEF staff and the YTP trainers and participants.

\section{Funding}

This essay was made possible by the generous support of the International Research Centre, Interweaving Performance Cultures.

\section{Notes}

1. Folk tale of Issyk-Kul lake orated by Anara Eginalieva from FTI.

2. Kyrgyzstan is surrounded by the mountainous borders of China to the east, Uzbekistan to the west, Kazakhstan to the north and Tajikistan to the south. Most of Kyrgyzstan was formally annexed to Russia in 1876. The Kyrgyz staged a major revolt against the Tsarist Empire in 1916 in which almost one-sixth of the Kyrgyz population was killed. Soviet power was initially established in the region in 1918. Kyrgyzstan became a Soviet republic in 1936 and achieved independence in 1991 when the USSR dissolved. Since 1991, there have been three presidents and two revolutions - known as the Tulip revolutions that occurred in 2005 and 2010 - evoked by other colour revolutions including the Orange Revolution in Ukraine in 2004 and the Rose Revolution in Georgia in 2003. Kyrgyzstan was ratified as a parliamentary republic after the adoption of the constitution in 2010.

3. Sholpan Davletova, 'Eco-Spirituality in Ancient Beliefs of Central Asian Nomads' Proceedings of the Fifth International Conference of The Asian Philosophical Association, Fukuoka, Japan, 2011. http://www.academia.edu/4529034/Eco-Spirituality_in_Ancient_Beliefs_of_ Central_Asian_Nomands (accessed 28 April 2014).

4. Borders are contentious; only 489 of the overall 972 kilometres of the border between Tajikistan and Kyrgyzstan has been fixed, 58 land parcels on the Uzbek-Kyrgyz border remains in contention, and heightened border security in certain areas restricts local trade. EurasiaNet, Kyrgyzstan: Ambiguous Kyrgyz-Tajik border increases risk of conflict, 2 February 2009. http://tinyurl.com/r4ue6r (accessed 8 March 2012).

5. I use the term cultural forms from the usage by Sir Edward Burnett Tylor (1832-1917) as 'that complex whole that includes knowledge, belief, art, morals, law, custom, and any other capabilities and habits acquired by man as a member of society'. See http://answers. yahoo.com/question/index?qid=20071106135057AAMdi05 (Tylor 1871, p. 1, emphasis added).

6. See Nurlan Asanbekov: Stage director is the one who wants to exhibit his theatre before the world http://www.imhoart.uz/en/being-there/1787-nurlan-asanbekov-stage-director-is-theone-who-wants-to-exhibit-his-theatre-before-the-world.html (accessed 21 October 2013). 
7. Text adapted by author from the original folk tale located in the Appendix for further clarity (Bellér-Hann and Sharshenova 2011).

8. Interview with Nurlan Asanbekov. Interview conducted by author. Bishkek, Kyrgyzstan, 31 May 2014.

9. The figure includes beneficiaries of the YTP project implemented in Kyrgyzstan and Tajikistan by IREX and the Interaction of Young People: across ethnic lines and public discourse on youth's role in building peace and strengthening tolerance project by UNICEF, with the same framework and lead facilitator.

10. http://www.irex.org/project/youth-theater-peace (accessed 1 May 2014).

Keywords: socially engaged performance; environmental aesthetics; conflict

\section{References}

Bellér-Hann, Ildikó, and Raushan Sharshenova. 2011. "Crossing Boundaries, Breaking Rules: Continuity and Social Transformation in Trickster Tales from Central Asia." Oral Tradition 26 (1): 71-124.

Casey, S. Edward. 1996. "How to Get from Space to Place in a Fairly Short Stretch of Time." In Senses of Place, edited by Steven Feld and Keith H. Basso. Santa Fe: School of American Research Press.

Cohen, Cynthia E., Roberto Gutiérrez Varea, and Polly O. Walker. 2011. Acting Together: Performance and the Creative Transformation of Violence: Volume l: Resistance and Reconciliation in Regions of Violence. New York: New Village Press.

Kleinbach, Russell, and Lilly Salimjanovoa. 2007. "Kyz ala kachuu and adat: Non-consensual Bride Kidnapping and Tradition in Kyrgyzstan." Central Asian Survey 26 (2): 217-233.

Martin, J., and A. Sauter. 1995. Understanding Theatre. Stockholm, Almqvist \& Wiksell International.

Sepänmaa, Yrjö. 1986. The Beauty of Environment: A General Model for Environmental Aesthetics. Helsinki: Suomalainen Tiedeaka-Temia.

van der Heide, Nienke. 1970. "Spirited Performance: The Manas Epic and Society in Kyrgyzstan." Doctoral Thesis, University of Tilburg. 